\title{
Effects of Allopurinol and Deferoxamine on Reperfusion Injury of the Brain in Newborn Piglets after Neonatal Hypoxia-Ischemia
}

\author{
CACHA PEETERS-SCHOLTE, KEES BRAUN, JOHANNA KOSTER, NICOLE KOPS, \\ KLAS BLOMGREN, GIUSEPPE BUONOCORE, SYLVIA VAN BUUL-OFFERS, HENRIK HAGBERG, \\ KLAAS NICOLAY, FRANK VAN BEL, AND FLORIS GROENENDAAL

\begin{abstract}
Departments of Neonatology [C.P.S., J.K., F.v.B., F.G.], Paediatric Endocrinology [J.K., N.K., S.v.B.-O.], and Experimental In Vivo NMR, Image Sciences Institute [K.Br., K.N.], University Medical Center, 3584 EA Utrecht, the Netherlands, Perinatal Center, Department of Physiology and Pharmacology, Göteborg University, 40530 Göteborg, Sweden [K.Bl., H.H.], and Institute of Preventive Paediatrics and Neonatology, University of
\end{abstract} Siena, I-53100 Siena, Italy [G.B.]

\begin{abstract}
The hypothesis was tested that treatment with allopurinol, a xanthine oxidase inhibitor, or deferoxamine, a chelator of nonprotein-bound iron, preserved cerebral energy metabolism, attenuated development of edema, and improved histologic outcome in the newborn piglet at $24 \mathrm{~h}$ after hypoxia-ischemia. Thirty-two newborn piglets were subjected to $1 \mathrm{~h}$ of hypoxia-ischemia by occluding both carotid arteries and reducing the fraction of inspired oxygen; five newborn piglets served as sham-operated controls. The depth of hypoxia-ischemia was controlled by phosphorous magnetic resonance spectroscopy. Upon reperfusion and reoxygenation, piglets received vehicle $(n=12)$, allopurinol (30 $\mathrm{mg} / \mathrm{kg} / \mathrm{d}, n=10)$, or deferoxamine $(12.5 \mathrm{mg} / \mathrm{kg} / \mathrm{d}, n=10)$. The cerebral energy status was determined with phosphorous magnetic resonance spectroscopy. The presence of vasogenic edema was assessed by $\mathrm{T} 2$-weighted magnetic resonance imaging. Brain cell injury was assessed with caspase-3 activity, histology, and terminal deoxynucleotidyl transferase-mediated dUTP-biotin in situ nick end (TUNEL)-labeling. At $24 \mathrm{~h}$ after hypoxia-ischemia, the phosphocreatine/inorganic phosphate ratios were significantly decreased in vehicle-treated, but not in allopurinol- or deferoxamine-treated piglets. Water T2 values were significantly
\end{abstract}

\section{ABSTRACT}

increased at $24 \mathrm{~h}$ after hypoxia-ischemia in cerebral cortex, thalamus, and striatum of vehicle-treated piglets, but not in allopurinol- and deferoxamine-treated piglets. No differences in caspase-3 activity, histologic outcome, or TUNEL-labeling were demonstrated between the three treatment groups. We suggest that allopurinol and deferoxamine may have an additional value in the treatment of perinatal hypoxia-ischemia with other neuroprotective agents or in combination with hypothermia. (Pediatr Res 54: 516-522, 2003)

BE, base excess

\section{Abbreviations}

$\mathrm{Fio}_{2}$, fraction of inspired oxygen

NPBI, nonprotein-bound iron

MABP, mean arterial blood pressure

MRI, magnetic resonance imaging

PCr, phosphocreatine

Pi, inorganic phosphate

${ }^{31}$ P-MRS, phosphorous magnetic resonance spectroscopy

TUNEL, terminal deoxynucleotidyl transferase-mediated dUTP-biotin in situ nick end labeling
The neonatal brain appears to be vulnerable to oxidative stress after perinatal hypoxia-ischemia with reperfusion and reoxygenation due to excessive free radical production, relatively large amounts of NPBI production, and inadequate

Received October 28, 2002; accepted April 11, 2003.

Correspondence: Floris Groenendaal, M.D., Ph.D., Department of Neonatology, Room KE.04.123.1, Wilhelmina Children's Hospital, University Medical Center Utrecht, P.O. Box 85090, 3508 AB Utrecht, the Netherlands; e-mail: F.Groenendaal@wkz.azu.nl

Supported by the Netherlands Organization for Scientific Research (NWO-AGIKO stipend 920-03-039) and the University Medical Center Utrecht ("Sterproject”). Oxford Instruments provided a cerebral function monitor, and Tyco Healthcare provided a Nellcor NPB-290 pulse oximeter.

DOI: 10.1203/01.PDR.0000081297.53793.C6 scavenging mechanisms to counteract these potentially neurotoxic events (1). During perinatal hypoxia-ischemia and upon reperfusion, a biochemical cascade occurs, including modification of the NMDA receptor-ion channel complex, leading to increased intracellular $\mathrm{Ca}^{2+}$ and resulting in the conversion of xanthine dehydrogenase to xanthine oxidase (2). During the primary hypoxic-ischemic insult, ADP is degraded to hypoxanthine and then oxidated to xanthine and on to uric acid by xanthine oxidase upon reperfusion [for review, see Fellman and Raivio (3)]. During these reactions, superoxide and hydrogen peroxide are formed, which can be converted to the highly reactive hydroxyl radical through the Haber-Weiss reaction, catalyzed by ferrous iron (4). The reactive oxygen species 
produced in this way can result in modification of the mitochondrial membrane, eventually leading to cell membrane and DNA damage, cytochrome $c$ leakage, caspase activation, and DNA fragmentation, and, subsequently, to secondary cell death.

After hypoxia-ischemia, secondary energy failure occurs from about $6 \mathrm{~h}$ after the insult, depending on the duration and intensity of the hypoxic-ischemic insult (5). This process can be studied with ${ }^{31} \mathrm{P}-\mathrm{MRS}$, as performed earlier in a newborn piglet model of perinatal asphyxia (6). Previous studies in animals and neonates showed that treatment with allopurinol, a xanthine oxidase inhibitor, upon reperfusion preserved the cerebral hemodynamics and electrocortical brain activity and showed neuroprotective effects (7-10). Short-term survival studies in newborn lambs and in dogs demonstrated beneficial effects of deferoxamine, a chelator of NPBI, on the amplitude-integrated EEG, cerebral blood flow, and metabolic decay $(7,11)$. However, effects of allopurinol and deferoxamine on cerebral energy status, amount of vasogenic edema, and histology at $24 \mathrm{~h}$ after the hypoxic-ischemic insult have not been studied previously. We hypothesized that allopurinol and deferoxamine had neuroprotective effects in a piglet model of perinatal hypoxia-ischemia with respect to the beforementioned parameters.

\section{MATERIALS AND METHODS}

Animal preparation and instrumentation. Thirty-two newborn Dutch store piglets, gestational age $115 \pm 1 \mathrm{~d}$ (mean \pm SEM), weight $1.69 \pm 0.16 \mathrm{~kg}$, were used with a postnatal age range from 1 to $3 \mathrm{~d}$ (12). Anesthesia was induced with $4 \%$ isoflurane in a $\mathrm{N}_{2} \mathrm{O} / \mathrm{O}_{2}$ mixture $(79 \% / 21 \%)$. After intubation, the piglets were mechanically ventilated using a continuous flow, pressurecontrolled ventilator (Amsterdam infant ventilator, HoekLoos, Amsterdam, the Netherlands). Anesthesia was maintained during the procedure using $1.5 \%$ isoflurane in the same $\mathrm{N}_{2} \mathrm{O} / \mathrm{O}_{2}$ mixture. Venous catheters were inserted for continuous infusion of glucose $5 \% / \mathrm{NaCl} 0.45 \%(5 \mathrm{~mL} / \mathrm{kg} / \mathrm{h})$ and drug infusion. Before each skin incision, local anesthesia with lidocaine $1 \%$ was applied. A catheter was advanced in the right femoral artery for continuous measurement of the MABP, and the blood was heparinized [5 units $(\mathrm{U}) / \mathrm{h}]$. Remotely inflatable vascular cuffs $(\mathrm{OC} 2 \mathrm{a}$, In vivo Metric, Healdsburg, CA, U.S.A.) were placed around both common carotid arteries at the level of the thyroid cartilage. Amoxicillin $(100 \mathrm{mg} / \mathrm{kg} / \mathrm{d})$, gentamicin $(5 \mathrm{mg} / \mathrm{kg} / \mathrm{d})$, and atropine $(0.01$ $\mathrm{mg} / \mathrm{kg}$ ) were administered intravenously. During the experiment, rectal temperature was measured and maintained between $38^{\circ}$ and $39^{\circ} \mathrm{C}$ using a heat lamp and/or water blanket.

The Animal Research Committee of the Utrecht University, the Netherlands, approved experimental protocols.

Experimental protocol. After completion of the surgical procedure, the piglets were allowed to achieve hemodynamic stability. Thereafter, the piglets were transferred to the MR unit for baseline ${ }^{31} \mathrm{P}$-MRS measurements. During these measurements, anesthesia was maintained with $1.5 \%$ isoflurane in an $\mathrm{O}_{2} / \mathrm{N}_{2} \mathrm{O}$ mixture $(30 \% / 70 \%)$. Animals were paralyzed with pancuronium bromide $(0.25 \mathrm{mg} / \mathrm{kg}$ i.v.). Piglets were subjected to $1 \mathrm{~h}$ of hypoxia-ischemia by inflating the occluders surrounding both common carotid arteries and reducing the $\mathrm{Fio}_{2}$ until the $\mathrm{PCr} / \mathrm{Pi}$ ratios had decreased to at least $30 \%$ of baseline values, as guided by frequent ${ }^{31} \mathrm{P}-\mathrm{MRS}$ measurements, for approximately $45 \mathrm{~min}$ of the 1-h hypoxic-ischemic period. When severe systemic hypotension (MABP $<30 \mathrm{~mm} \mathrm{Hg}$ ) or bradycardia developed, the $\mathrm{Fio}_{2}$ was minimally increased to prevent further decrease of blood pressure or to obtain recovery of the heart rate. Isoflurane administration was discontinued from $10 \mathrm{~min}$ after start of hypoxiaischemia until $10 \mathrm{~min}$ after reperfusion to reduce the effect of anesthetics on cardiovascular stability during the actual insult, but the administration of $\mathrm{N}_{2} \mathrm{O}$ was continued. After $1 \mathrm{~h}$ of hypoxiaischemia, the occluders were deflated and the oxygen intake increased to obtain normoxia (partial pressure of arterial oxygen, $80-120 \mathrm{~mm} \mathrm{Hg}$ ), carefully avoiding hyperoxia. The piglets were randomly assigned to receive vehicle $(5 \mathrm{~mL} / \mathrm{kg}$ i.v. $0.9 \% \mathrm{NaCl})$; allopurinol (Multipharma, Weesp, the Netherlands), $20 \mathrm{mg} / \mathrm{kg}$ upon reperfusion and a repeated dose of $10 \mathrm{mg} / \mathrm{kg}$ at $12 \mathrm{~h}$; or deferoxamine (Novartis, Basel, Switzerland), $10 \mathrm{mg} / \mathrm{kg}$ upon reperfusion and a repeated dose of $2.5 \mathrm{mg} / \mathrm{kg}$ at $12 \mathrm{~h}$, injected intravenously by a perfusor pump over $15 \mathrm{~min}$. Five additional piglets served as sham-operated controls and were not subjected to hypoxia-ischemia. MABP, heart rate, oxygen saturation using a pulse oxymeter (Nellcor NPB-290, Tyco Healthcare, Pleasanton, CA, U.S.A.), and rectal temperature were measured during the study protocol. Sampling of arterial blood gases, arterial $\mathrm{pH}$, and glucose was performed at baseline, at the end of $1 \mathrm{~h}$ of hypoxiaischemia, and at $24 \mathrm{~h}$ of reperfusion. Between $3 \mathrm{~h}$ and $24 \mathrm{~h}$ after the start of hypoxia-ischemia, the piglets were observed in the piglet intensive care unit. At $24 \mathrm{~h}$ after reperfusion, the piglets were transferred to the MR unit and ${ }^{31} \mathrm{P}-\mathrm{MRS}$ measurements were repeated.

${ }^{31} \boldsymbol{P}$-MRS. ${ }^{31} \mathrm{P}$-MRS experiments were performed at $81 \mathrm{MHz}$ on an INOVA console (Varian, Palo Alto, CA, U.S.A.) interfaced to a $4.7 \mathrm{~T}$ Oxford magnet with a bore size of $40 \mathrm{~cm}$. A $\varnothing 4-\mathrm{cm}$ surface coil was used for signal excitation and nonlocalized detection and placed onto the intact scalp over the parietal lobes. A 1.0-ms adiabatic half passage pulse was used for excitation. To minimize $\mathrm{T} 1$ effects, a repetition time of $10 \mathrm{~s}$ was used. Thirty-two acquisitions were averaged at baseline and during reperfusion and eight acquisitions during hypoxia-ischemia to evaluate the depth of hypoxia-ischemia. Peak amplitudes of PCr and Pi were determined with time-domain fitting procedures using prior knowledge (Variable Projection Method; Magnetic Resonance User Interface 97.2, Universitat Autònoma de Barcelona, Barcelona, Spain) (13).

Metabolite ratios of $\mathrm{PCr} / \mathrm{Pi}$ were calculated. To determine whether the decline in the energy status during the 1-h period of hypoxia-ischemia was the same for the different groups, areas under the $\mathrm{PCr} / \mathrm{Pi}$ curve were determined for each piglet (GraphPad Prism version 3.00 for Windows, GraphPad Software, San Diego, CA, U.S.A.).

T2-weighted MRI. T2-weighted multislice spin-echo MRI was performed at baseline and at $24 \mathrm{~h}$ after hypoxia-ischemia using a birdcage volume coil. Repetition time was $3 \mathrm{~s}$; echo times were 25,40 , and $70 \mathrm{~ms}$; and a slice sickness of $2 \mathrm{~mm}, 16$ slices and two transitions, was used. Quantitative T2 maps were generated from these T2-weighted MR images and time course changes of T2 relaxation times were assessed in brain areas known to be sensitive to hypoxia-ischemia, e.g. cortex, striatum, thalamus and white matter, at baseline and $24 \mathrm{~h}$ after hypoxia-ischemia. These regions 
of interest were manually drawn in the T2 maps to average regional T2 values, with the use of the image analysis software package Image Browser (Varian).

Allopurinol and oxypurinol levels in serum. Serum samples were taken at $0.5,1.5,2,3$, and $12 \mathrm{~h}$ after the first gift of allopurinol and 0.5 and $12 \mathrm{~h}$ after the second gift of allopurinol for assessment of allopurinol and oxypurinol levels. For the analysis of serum and brain tissue, a modified reversed-phase high-pressure liquid-chromatographic method with UVdetection according to Wung and Howel (14) was used.

Assay of caspase-3 like activity. The experiment was ended at $24 \mathrm{~h}$ after hypoxia-ischemia by an overdose of pentobarbital, and the brain was rapidly perfused with normal saline to remove the excess of blood. Right hemispheres of all piglets were dissected into cortex, striatum, thalamus, and white matter and were snap frozen in liquid nitrogen and stored at $-80^{\circ} \mathrm{C}$ until further analysis. Tissue pieces were homogenized by sonication in 10 volumes of ice-cold $50 \mathrm{mM}$ Tris- $\mathrm{HCl}(\mathrm{pH} 7.3)$, containing $5 \mathrm{mM}$ EDTA, aliquoted and stored at $-80^{\circ} \mathrm{C}$. The protein concentrations were determined according to Whitaker and Granum (15), adapted for microplates using a Spectramax Plus plate reader (Molecular Devices, Menlo Park, CA, U.S.A.). Samples of homogenate $(25 \mu \mathrm{L})$ were mixed with 75 $\mu \mathrm{L}$ of extraction buffer, containing $50 \mathrm{mM}$ Tris- $\mathrm{HCl}(\mathrm{pH} 7.3)$, $100 \mathrm{mM} \mathrm{NaCl}, 5 \mathrm{mM}$ EDTA, 1 mM EGTA, 3 mM NaN3, 1 $\mathrm{mM}$ phenylmethylsulfonyl fluoride, $1 \mu \mathrm{g} / \mathrm{mL}$ pepstatin, 2.5 $\mu \mathrm{g} / \mathrm{mL}$ leupeptin, $10 \mu \mathrm{g} / \mathrm{mL}$ aprotinin, and $0.2 \% 3-[(3-$ cholamidopropyl)dimethylammonio]-1-propanesulfonate (CHAPS), on a microtiter plate (Microfluor; Dynatech Labs, Chantilly, VA, U.S.A.). After incubation for $15 \mathrm{~min}$ at room temperature, $100 \mu \mathrm{L}$ of peptide substrate, $50 \mu \mathrm{M}$ Ac-Asp-GluVal-Asp-AMC (Ac-DEVD-AMC, from Enzyme Systems Products, Livermore, CA, U.S.A.) in extraction buffer without inhibitors or CHAPS, but with 4 mM DTT, was added. Cleavage of DEVD-AMC was measured at $37^{\circ} \mathrm{C}$ using a Spectramax Gemini microplate fluorometer (Molecular Devices) with an excitation wavelength of $380 \mathrm{~nm}$ and an emission wavelength of $460 \mathrm{~nm}$, and expressed as picomoles AMC released per milligram protein and per minute.

NPBI levels in serum and brain. NPBI plasma levels at baseline and at $24 \mathrm{~h}$ after hypoxia-ischemia were detected by HPLC using the method described by Kime et al. (16) partially modified. The system was operated isocritically at a pressure of approximately $115 \mathrm{Bar}$ and flow of $0.75 \mathrm{~mL} / \mathrm{min}$. The detection wavelength was $450 \mathrm{~nm}$ with a reference wavelength at 620 $\mathrm{nm}$. A low-affinity ligand, disodium nitryloacetic acid, was first used to complex all low-molecular-weight iron and iron nonspecifically bound to serum proteins such as albumin. Because it does not remove iron bound to transferrin or ferritin, a two-step filtration process was used: filtration with a $100-\mathrm{kD}$ molecular weight cut-off ultracentrifuge filter (Whatman, Clifton, NJ, U.S.A.) was followed by filtration with one having a cut-off at $20 \mathrm{kD}$. The filtrate was analyzed by direct injection into a reverse-phase liquid chromatography system, using precolumn derivatization with the high-affinity iron chelator CP22 (3-hydroxyl-1-propyl-2-methyl-pyridin-4-one hydrochloride). The system is able to detect iron in a ferric nitrate standard at a concentration as low as $0.02 \mu \mathrm{M}$. NPBI brain levels were expressed as micromole per gram of tissue.

Histology. Left hemispheres of all piglets were removed after intracardial perfusion with $4 \%$ phosphate-buffered formaldehyde and were processed for light microscopy. The hemispheres were accurately placed into a self-made leaden mall and were cut at fixed intervals into three parts for easier processing for light microscopy. Coronal sections $(7 \mu \mathrm{m})$ of these brain parts were cut, mounted on a silan-coated glass slide and stained with cresyl violet. The striatum was counted at $17.50 \mathrm{~mm}$ in the anterior plane, as shown in a stereotaxic atlas of the pig brain (17). The parietal cortex and hippocampus were both counted at $3.00 \mathrm{~mm}$ in the posterior plane (17). Quantification of neuronal viability was performed in the central three lobes of the parietal cortex and in the caput of the caudate nucleus of the striatum using a grid of 100 compartments at $200 \times$ magnification. All normal-appearing neurons in the CA 1, CA 2, CA 3, and CA 4 region of the hippocampus and the dentate gyrus were counted. The averaged value was used as the amount of normal-appearing cells in the hippocampus.

Apparently normal neurons were morphologically identified by the presence of typical nuclei with clear nucleoplasm and a distinct nucleolus, surrounded by purple-stained cytoplasm. Neurons were defined as damaged when no distinction could be made between nucleus and cytoplasm (pyknotic or necrotic).

TUNEL labeling. DNA fragmentation was assessed with TUNEL labeling using an in situ detection kit (ApopTag peroxidase kit; Intergen, Purchase, NY, U.S.A.). The presence of positively stained nuclei was assessed in cortex, striatum and hippocampus at $200 \times$ magnification. A global estimation of TUNEL-positive cells on a three-point scale was made, as described previously (12): a score of 1 (mild) was assigned to piglets with $<25 \%$ staining of the nuclei, a score of 2 (moderate) to piglets with nuclear staining between 25 and $75 \%$, and a score of 3 (severe) to staining of the nuclei of $>75 \%$.

Statistical analysis. Data are presented as mean \pm SEM. Testing for independent samples was performed with the Kruskal-Wallis test. The Wilcoxon signed rank test was used for two dependent samples. Bonferroni correction for multiple testing was performed when appropriate. MRS and MRI data from piglets that died prematurely were left out at the 24-h posthypoxic-ischemic time points, unless the piglets died with a persistently isoelectric amplitude-integrated EEG during the period of secondary energy failure (two vehicle-treated and one allopurinol-treated piglet) (18). Then, the $\mathrm{PCr} / \mathrm{Pi}$-ratios were considered to be zero. For histology the brain halves were collected at $24 \mathrm{~h}$ or at earlier time points in case of premature death. Ordinal data for TUNEL labeling and nitrotyrosylation were assessed with cross-tabulations using Gamma testing. With an expected variation coefficient of $10 \%$ and an expected relative effect of $20 \%$, power analysis revealed that groups of 10 animals each would be sufficient to demonstrate these differences with a $\beta$ of 0.10 and $\alpha$ of 0.05 . A $P$ value $<0.05$ was considered statistically significant.

\section{RESULTS}

Physiologic data. Animal weight, sex, and gestational and postnatal ages were equally distributed among groups. Three 
vehicle-, one allopurinol-, and one deferoxamine-treated piglets died between $5 \mathrm{~h}$ and $19 \mathrm{~h}$ after hypoxia-ischemia due to posthypoxic-ischemic complications such as cardiac failure or gut necrosis (not statistically different). MABP, heart rate, arterial $\mathrm{pH}$, arterial $\mathrm{P}_{2}$, and $\mathrm{BE}$ values are shown in Table 1 . No significant differences were detected between groups at baseline, the end of hypoxia-ischemia, and at $24 \mathrm{~h}$ after hypoxia-ischemia. As expected, a significant increase in heart rate and a decrease in $\mathrm{pH}$ and $\mathrm{BE}$ was observed in all groups during the hypoxic-ischemic insult compared with baseline values. In vehicle-treated piglets, the heart rate remained significantly increased at $24 \mathrm{~h}$ after hypoxia-ischemia, whereas in allopurinol-treated piglets, the BE was significantly increased at $24 \mathrm{~h}$ compared with baseline values. There were no relevant changes in arterial $\mathrm{PCO}_{2}$, glucose, and rectal temperature during the study period for all treatment groups.

Sham-operated piglets did not show differences in MABP, heart rate, arterial $\mathrm{pH}, \mathrm{PCO}_{2}$, and $\mathrm{BE}$ levels over time (data not shown).

${ }^{31} \boldsymbol{P}$-MRS. Table 2 shows the $\mathrm{PCr} / \mathrm{Pi}$ ratio, a sensitive indicator for the energy status of the brain tissue, for all treatment groups at baseline, at the end of $1 \mathrm{~h}$ of hypoxia-ischemia, and at $24 \mathrm{~h}$ after hypoxia-ischemia. During hypoxia-ischemia, there was a rapid, significant decline in $\mathrm{PCr} / \mathrm{Pi}$ ratios to $\leq 30 \%$ of baseline values in all groups as intended $(p<0.005)$. The decrease of $\mathrm{PCr} / \mathrm{Pi}$ during the 1-h hypoxic-ischemic insult was similar in the vehicle-, allopurinol-, and deferoxamine-treated groups. Vehicle-treated piglets showed a significant reduction in cerebral energy status at $24 \mathrm{~h}$ after hypoxia-ischemia compared with baseline $(p<0.005)$. Preservation of the cerebral energy status was observed in allopurinol- and deferoxamine-treated piglets at $24 \mathrm{~h}$ after hypoxia-

Table 1. Physiological data at baseline, at the end of $1 \mathrm{~h}$ of hypoxia-ischemia (HI), and at $24 \mathrm{~h}$ after HI for vehicle $(n=12)$, allopurinol $(n=10)$, and deferoxamine $(n=10)$ treated piglets

\begin{tabular}{lccc}
\hline & Baseline & End of $\mathrm{HI}$ & $\begin{array}{c}24 \mathrm{~h} \text { after } \\
\text { start of } \mathrm{HI}\end{array}$ \\
\hline MABP (mm Hg) & & & \\
Vehicle & $55 \pm 4$ & $75 \pm 8$ & $58 \pm 5 \dagger$ \\
Allopurinol & $57 \pm 2$ & $68 \pm 8$ & $49 \pm 4$ \\
Deferoxamine & $52 \pm 2$ & $65 \pm 6$ & $62 \pm 4$ \\
HR (beats/min) & & & \\
Vehicle & $160 \pm 7$ & $210 \pm 14^{*}$ & $194 \pm 15^{*}$ \\
Allopurinol & $168 \pm 8$ & $247 \pm 12^{*}$ & $189 \pm 11 \dagger$ \\
Deferoxamine & $155 \pm 7$ & $218 \pm 15^{*}$ & $200 \pm 13$ \\
$\mathrm{pH}$ & & & \\
Vehicle & $7.34 \pm 0.02$ & $7.11 \pm 0.05^{*}$ & $7.43 \pm 0.03 \dagger$ \\
Allopurinol & $7.34 \pm 0.02$ & $7.22 \pm 0.04^{*}$ & $7.48 \pm 0.05 \dagger$ \\
Deferoxamine & $7.36 \pm 0.02$ & $7.12 \pm 0.04^{*}$ & $7.42 \pm 0.02 \dagger$ \\
Paco (mm Hg) & & & \\
Vehicle & $44 \pm 2$ & $46 \pm 3$ & $39 \pm 3$ \\
Allopurinol & $48 \pm 3$ & $40 \pm 4$ & $38 \pm 5$ \\
Deferoxamine & $39 \pm 2$ & $46 \pm 3$ & $39 \pm 3$ \\
$\mathrm{BE}$ (mmol/L) & & & \\
Vehicle & $-1.7 \pm 1.4$ & $-13.6 \pm 1.7^{*}$ & $1.7 \pm 2.1 \dagger$ \\
Allopurinol & $-0.6 \pm 1.3$ & $-10.5 \pm 1.4^{*}$ & $4.2 \pm 1.0 \dagger$ \\
Deferoxamine & $-3.3 \pm 1.3$ & $-15.0 \pm 1.8^{*}$ & $0.7 \pm 1.0 \dagger$ \\
\hline
\end{tabular}

Values are mean \pm SEM. Wilcoxon signed rank test after Bonferroni correction for multiple testing. HR, heart rate.

$* p<0.05 v s$ baseline; $\dagger p<0.05 v s$ end of $1 \mathrm{~h}$ of hypoxia-ischaemia.
Table 2. $P C r / P i$ ratios ratios of vehicle- $(n=12)$, allopurinol $(n=10)$, and deferoxamine-treated piglets $(n=10)$ during baseline, at the end of $1 \mathrm{~h}$ of hypoxia-ischaemia (HI) and at $24 \mathrm{~h}$ post-HI

\begin{tabular}{lccc}
\hline & Baseline & End of HI & 24 h after start of HI \\
\hline Vehicle & $2.37 \pm 0.22$ & $0.40 \pm 0.10^{* *}$ & $0.80 \pm 0.24^{* *}$ \\
Allopurinol & $2.52 \pm 0.22$ & $0.31 \pm 0.08^{* *}$ & $1.53 \pm 0.47$ \\
Deferoxamine & $3.08 \pm 0.42$ & $0.21 \pm 0.05^{* *}$ & $1.97 \pm 0.46 \dagger$ \\
\hline
\end{tabular}

Values are mean \pm SEM. Wilcoxon signed rank test after Bonferroni correction for multiple testing, ${ }^{* *} p<0.005 v s$ baseline; $\uparrow p<0.05 v s$ end of hypoxia-ischemia (HI).

ischemia compared with baseline. $\mathrm{PCr} / \mathrm{Pi}$ ratios of sham-operated piglets varied from $1.70 \pm 0.31$ at baseline to $1.52 \pm 0.16$ at $24 \mathrm{~h}$ (not significantly different).

\section{MRI}

Water T2 values, which are a sensitive indicator of the possible development of vasogenic edema, are presented in Table 3. Water T2 in the cerebral cortex, striatum, and thalamus was significantly prolonged at $24 \mathrm{~h}$ after hypoxia-ischemia compared with baseline in the vehicle-treated, but not in the allopurinol- or deferoxamine-treated piglets. No changes in T2 values were seen in white matter in all treatment groups.

\section{CASPASE-3 ACTIVITY}

No significant differences in caspase-3 activity were present between treatment groups at $24 \mathrm{~h}$ in cortex, hippocampus, striatum, thalamus, or white matter (Table 4).

\section{ALLOPURINOL AND OXYPURINOL LEVELS IN SERUM}

Allopurinol and oxypurinol levels for the allopurinol-treated piglets during the 24-h period of reperfusion are shown in Figure. 1. Allopurinol levels ranged from $22 \mathrm{mg} / \mathrm{L}$ directly after the first injection to $6 \mathrm{mg} / \mathrm{L}$ at 12 and $24 \mathrm{~h}$ after reperfusion. Oxypurinol

Table 3. Water T2 values (mean \pm SEM in $\mathrm{ms})$ of vehicle- $(n=$ 12), allopurinol- $(n=10)$, and deferoxamine-treated piglets $(n=10)$ at baseline and at $24 \mathrm{~h}$ after hypoxia-ischemia (HI)

\begin{tabular}{llr}
\hline & Baseline & $24 \mathrm{~h}$ after $\mathrm{HI}$ \\
\hline Cortex & & \\
Vehicle & $80 \pm 3$ & $93 \pm 5^{*}$ \\
Allopurinol & $93 \pm 6$ & $107 \pm 12$ \\
Deferoxamine & $85 \pm 5$ & $96 \pm 11$ \\
Striatum & & \\
Vehicle & $72 \pm 2$ & $82 \pm 3^{*}$ \\
Allopurinol & $93 \pm 10$ & $90 \pm 10$ \\
Deferoxamine & $82 \pm 8$ & $83 \pm 8$ \\
Thalamus & & \\
Vehicle & $66 \pm 1$ & $68 \pm 1^{*}$ \\
Allopurinol & $84 \pm 10$ & $85 \pm 9$ \\
Deferoxamine & $73 \pm 6$ & $75 \pm 6$ \\
White matter & & \\
Vehicle & $59 \pm 1$ & $62 \pm 2$ \\
Allopurinol & $73 \pm 6$ & $71 \pm 6$ \\
Deferoxamine & $64 \pm 4$ & $66 \pm 6$
\end{tabular}

$* p<.05$ vs baseline, Wilcoxon signed rank test. 
Table 4. Caspase-3 activities (pg AMC released/mg protein-min) at $24 \mathrm{~h}$ after hypoxia-ischemia in vehicle- $(n=12)$, allopurinol-

$(n=10)$, and deferoxamine- $(n=10)$ treated piglets and in sham-operated piglets $(n=5)$

\begin{tabular}{lcccc}
\hline & Cortex & Striatum & Thalamus & White matter \\
\hline Vehicle & $5.0 \pm 1.4$ & $5.3 \pm 1.7$ & $3.8 \pm 3.0$ & $5.7 \pm 2.4$ \\
Allopurinol & $3.1 \pm 1.1$ & $2.5 \pm 0.9$ & $0.6 \pm 0.2$ & $2.4 \pm 1.0$ \\
Deferoxamine & $2.6 \pm 1.4$ & $2.2 \pm 1.4$ & $1.3 \pm 0.7$ & $2.5 \pm 1.4$ \\
Sham & $0.2 \pm 0.0$ & $0.3 \pm 0.0$ & $0.6 \pm 0.1$ & $0.4 \pm 0.1$ \\
\hline
\end{tabular}

No significant differences between vehicle-, allopurinol-, and deferoxaminetreated piglets were demonstrated. Values are mean \pm SEM.

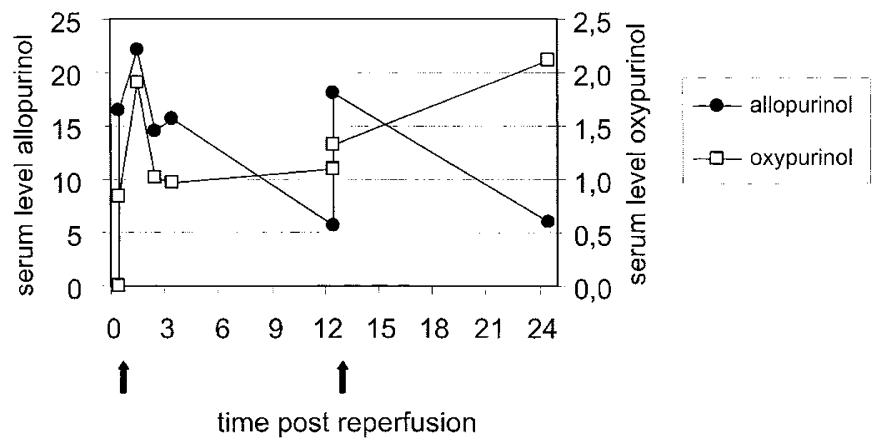

Figure 1. Serum allopurinol and oxypurinol levels. Mean serum allopurinol and oxypurinol levels $(\mathrm{mg} / \mathrm{L})$ during the $24 \mathrm{~h}$ reperfusion period $(n=5-10)$ at the different time points. Arrows indicate the administration of $20 \mathrm{mg} / \mathrm{kg}$ and $10 \mathrm{mg} / \mathrm{kg}$ allopurinol at $0 \mathrm{~h}$ and $12 \mathrm{~h}$, respectively.

levels ranged from $1.9 \mathrm{mg} / \mathrm{L}$ directly after injection of allopurinol and to $2.1 \mathrm{mg} / \mathrm{L}$ at $24 \mathrm{~h}$ after hypoxia-ischemia.

\section{NPBI LEVELS IN SERUM AND BRAIN}

No significant differences in NPBI levels in serum were found between groups at baseline and at $24 \mathrm{~h}$ after hypoxia-ischemia (Table 5). NPBI in brain tissue tended to be reduced in the deferoxamine-treated piglets at $24 \mathrm{~h}$ after hypoxia-ischemia, but it did not reach a significant difference due to the large SEM.

\section{HISTOLOGY}

No differences in amount of normal appearing cells were demonstrated between the treatment groups using cresyl violet staining (Table 6) or TUNEL labeling (Fig. 2).

\section{DISCUSSION}

In the present study, beneficial effects of allopurinol and deferoxamine were demonstrated at $24 \mathrm{~h}$ after hypoxiaischemia. Whereas secondary energy failure, i.e. a secondary decline in $\mathrm{PCr} / \mathrm{Pi}$ ratios, was demonstrated in the vehicletreated piglets compared with baseline levels, no significant

Table 5. NPBI levels in serum in $\mu \mathrm{mol} / \mathrm{L}$ at baseline and at $24 \mathrm{~h}$ after hypoxia-ischemia (HI) and in cortical brain tissue (in $\mu \mathrm{mol} / \mathrm{g}$ ) at $24 \mathrm{~h}$ after $\mathrm{HI}$

\begin{tabular}{lcccc}
\hline \multicolumn{1}{c}{ Serum } & Baseline & $24 \mathrm{~h}$ & Brain & $24 \mathrm{~h}$ \\
\hline Vehicle & $2.8 \pm 1.6$ & $6.5 \pm 4.9$ & & $36.2 \pm 18.4$ \\
Deferoxamine & $5.1 \pm 3.6$ & $2.9 \pm 1.1$ & & $8.9 \pm 3.6$ \\
Sham & $0.9 \pm 0.7$ & $0.1 \pm 0.1$ & & $12.0 \pm 4.0$ \\
\hline
\end{tabular}

Values are mean \pm SEM.
Table 6. Histology: piglets were either treated with vehicle $(n=12)$, allopurinol $(n=10)$, deferoxamine $(n=10)$ or were sham-operated $(n=5)$

\begin{tabular}{lccc}
\hline \multicolumn{1}{c}{ Histology } & Cortex & Striatum & Hippocampus \\
\hline Vehicle & $155 \pm 37$ & $222 \pm 60$ & $45 \pm 12$ \\
Allopurinol & $190 \pm 59$ & $210 \pm 52$ & $60 \pm 13$ \\
Deferoxamine & $207 \pm 45$ & $284 \pm 62$ & $65 \pm 11$ \\
Sham & $349 \pm 71$ & $409 \pm 23$ & $101 \pm 17$ \\
\hline
\end{tabular}

For histology, the number of normal-appearing neurons per field of examination is indicated. No significant differences were demonstrated between the treatment groups. Values are mean \pm SEM.

impairment in cerebral energy status was observed in either the allopurinol- and deferoxamine-treated piglets. Simultaneously, increased water $\mathrm{T} 2$ values were found only in the gray matter of vehicle-treated piglets. In contrast with these beneficial findings, no significant effects of allopurinol or deferoxamine were demonstrated on caspase-3 activity, histologic outcome, or TUNEL labeling at $24 \mathrm{~h}$ after hypoxia-ischemia.

Allopurinol. Peak allopurinol levels were above $20 \mathrm{mg} / \mathrm{L}$ in serum and minimal allopurinol levels were above $5 \mathrm{mg} / \mathrm{L}$. The allopurinol serum levels of the piglets in the present study showed a striking similarity to those of asphyxiated human neonates (8). From these levels it can be assumed that allopurinol was adequately dosed to achieve xanthine oxidase inhibition (10). Similar beneficial effects of allopurinol, i.e. preservation of brain energy status and reduced brain edema, comparable to those in the present study, have been previously observed in 7-d-old rats, treated before onset of hypoxiaischemia. Neuroprotection in these animals was confirmed with histology at $30 \mathrm{~d}$ after hypoxia-ischemia $(19,20)$. Neuroprotective effects of allopurinol administered after the insult have been observed in 7-d-old rats (10), and in newborn lambs (7). Reactive oxygen species-induced brain cell injury can be reduced through inhibition of xanthine oxidase, present in capillary endothelial cells (21), by allopurinol and oxypurinol (22). Other neuroprotective pathways of allopurinol are direct free radical scavenging demonstrated in vitro with high concentrations of allopurinol (23), inhibition of neutrophil accumulation (24), chelation of metal ions such as ferric iron (25), and facilitation of electron transport from ferrous iron to ferric cytochrome $c$ (26). In contrast with previous observations, no effects on caspase-3 activity, number of apparently normal neurons, or TUNEL labeling were found at $24 \mathrm{~h}$ after hypoxiaischemia. The discrepancy between the reduction of secondary energy failure and brain edema on the one hand, and the lack of histologic neuroprotection on the other hand, might suggest that cell populations in the brain may react differently to allopurinol. Neurons may be less protected than glial cells, whereas these functioning glial cells preserve brain energy status and do not contribute to brain edema. However, recently it has been shown that astroglial cells account for only $14 \%$ of the total brain oxygen consumption (27), which makes this suggestion unlikely. A more likely explanation is that administration of allopurinol increases the heterogeneity in the treatment group by rescuing only the moderately damaged piglets, whereas the severely damaged piglets can no longer be rescued. This heterogeneity in the severity of the brain injury 


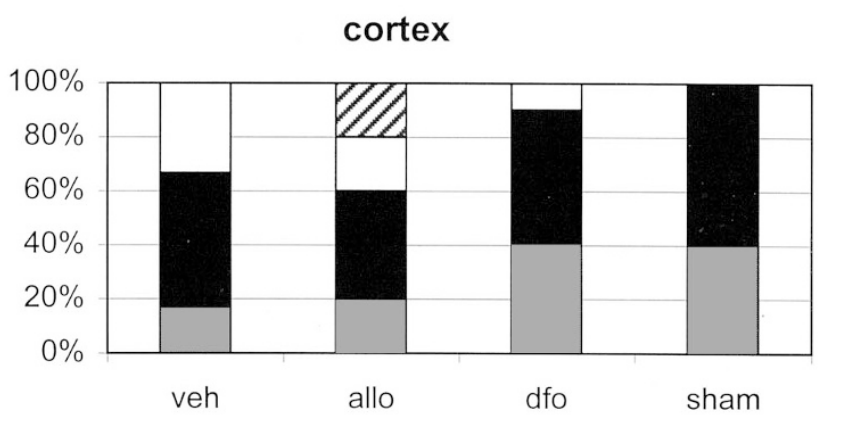

score 1 score $2 \square$ score $3 \square$ missing

striatum

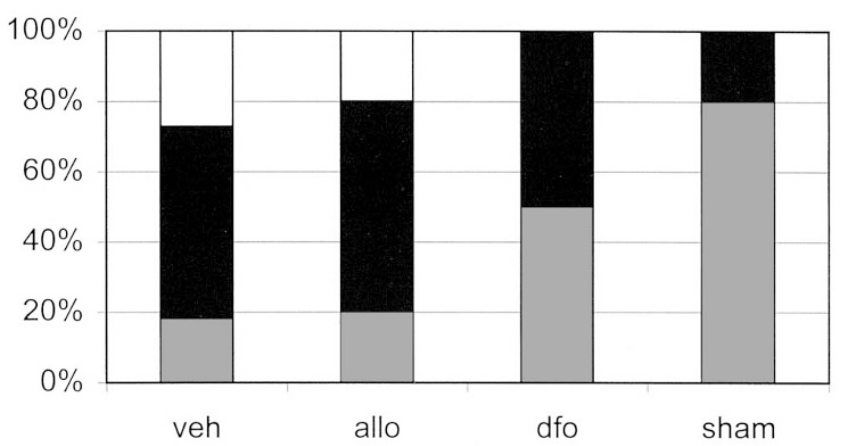

hippocampus

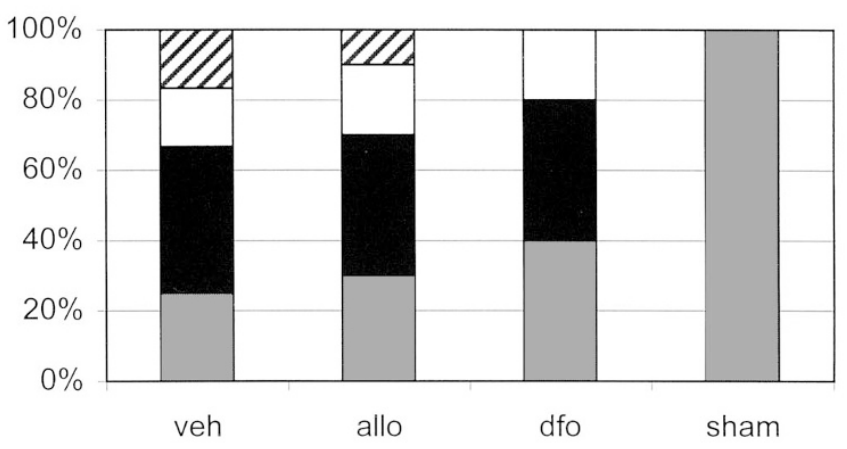

Figure 2. TUNEL score. Percentage of piglets with score 1 (mild, $<25 \%$ of cells stained), score 2 (moderate, $25-75 \%$ of cells stained), or score 3 (severe, $>75 \%$ of cells stained) on a three-point scale and percentage of piglets with a missing TUNEL labeling are indicated for TUNEL data in cortex, striatum, and hippocampus. No significant differences between groups were demonstrated.

cannot be predicted from ${ }^{31} \mathrm{P}$-MRS measurements during the insult because all piglets had a similar decrease of $\mathrm{PCr} / \mathrm{Pi}$ ratios, but rather it reflects individual differences of the piglets.

The increase in heterogeneity with rescue of the moderately damaged piglets only would explain the increase in SEM as seen in the $\mathrm{PCr} / \mathrm{Pi}$ ratios and water T2 values in cortical areas of allopurinol-treated piglets at $24 \mathrm{~h}$ after hypoxia-ischemia (Tables 2 and 3). Furthermore, it is unknown whether the effects of allopurinol on brain edema and brain energy are sustained beyond $24 \mathrm{~h}$ after the insult.
Regarding the safety of allopurinol in neonates and the effects of allopurinol on brain energy and edema, and notwithstanding the lack of beneficial effects on histology, we suggest that allopurinol may be used in a combination therapy after perinatal hypoxia-ischemia.

Deferoxamine. In the present study, positive effects of deferoxamine on cerebral energy status and the water $\mathrm{T} 2$ values were demonstrated. In previous studies, it was shown that deferoxamine had neuroprotective effects in rats, dogs, and sheep after hypoxia-ischemia, but less so in piglets $(7,11,28,29)$. For deferoxamine to be neuroprotective it must have access to intraand extracellular iron. Although studies have suggested that deferoxamine is incapable of crossing cell membranes effectively, it does accumulate in the lysosomes and complexes with intralysosomal iron (30). Furthermore, it was shown that deferoxamine can enter the brain of a 7-d-old rat exposed to hypoxia-ischemia (28). A deferoxamine-mediated reduction in brain iron content and lipid peroxidation after hypoxia-ischemia in lambs supports this previous observation (31). NPBI levels in brain tissue tended to be lower in deferoxamine-treated animals as opposed to vehicletreated animals, but the differences did not reach significance. Measurements of NPBI were performed $12 \mathrm{~h}$ after the last dose of deferoxamine. It cannot be excluded that measurements at earlier time points, as have been performed in newborn lambs (31), would have resulted in more reduced levels of NPBI and may be species dependent. Alternatively, it could be argued that the dose of deferoxamine has been too low to obtain reductions of NPBI levels in the brain. The present dose of deferoxamine treatment was chosen, because deLemos et al. (32) described toxic effects of high-dose deferoxamine treatment on the cardiovascular system in baboons. Earlier studies in newborn lambs showed that even low-dose deferoxamine $(2.5 \mathrm{mg} / \mathrm{kg})$ led to a reduction in NPBI in the brain at $3 \mathrm{~h}$ after hypoxia-ischemia (31). With the present dose of $12.5 \mathrm{mg} / \mathrm{kg} / \mathrm{d}$ deferoxamine, we did not detect any negative effects.

Several mechanisms of action for deferoxamine treatment have been proposed. Firstly, deferoxamine binds ferric iron and thereby prevents the formation of the very potent hydroxyl radical via the Fenton/Haber-Weiss reaction (4). Secondly, deferoxamine can scavenge superoxide and hydroxyl radicals in concentrations of $0.5-1 \mathrm{mM}(28)$ and prevents neutrophilmediated killing of endothelial cells in cell cultures, which might reduce the inflammatory response after hypoxiaischemia and reperfusion (33). Previous studies in newborn lambs showed that rescue treatment with deferoxamine increased brain perfusion, whereas oxygen metabolism, electrocortical brain activity, and cortical neuronal cell membrane $\mathrm{Na}^{+}, \mathrm{K}^{+}$-ATP-ase activity were stable in the first $3.5 \mathrm{~h}$ after reperfusion and were comparable to baseline values $(7,34)$. In a clinical study in 50 severely asphyxiated full-term infants, children with severe birth asphyxia and an adverse outcome at 2 y of age had higher levels of NPBI in plasma during the first $8 \mathrm{~h}$ of life, which suggests a neurotoxic role of NPBI (35).

Again, as with allopurinol, deferoxamine resulted in preservation of cerebral energy status and preserved water T2 properties, indicating reduced vasogenic edema without effects on histologic outcome. Effects of deferoxamine may be different on glial cells and neurons. 
It is unknown whether brain edema at $24 \mathrm{~h}$ after hypoxiaischemia is a good predictor of long-term outcome. In view of this point, the observation that the MR-measured extent of cerebral edema $2 \mathrm{~d}$ after the insult in hypoxic-ischemic mice correlated with long-term histologic outcome is of interest (36).

In the present study, piglets were observed for $24 \mathrm{~h}$ after hypoxia-ischemia. Because Lorek et al. (6) reported that the secondary energy failure starts as early as $12 \mathrm{~h}$ after hypoxiaischemia, and no significant differences in $\mathrm{PCr} / \mathrm{Pi}$ ratios were demonstrated between 24 and $48 \mathrm{~h}$ after hypoxia-ischemia, the time point of $24 \mathrm{~h}$ was chosen to establish "early outcome." Therefore, in the present and in a previous study (6), a 24-h observation period after hypoxia-ischemia was considered a valid approach to examine the development of brain injury. It could be argued that, in the present study, the period of secondary energy failure was only postponed after the first $24 \mathrm{~h}$ after hypoxiaischemia. It needs to be stressed that definite conclusions can only be drawn from long-term follow-up studies.

\section{CONCLUSION}

In summary, the present study demonstrated that allopurinol and deferoxamine maintained cerebral energy status after global hypoxia-ischemia in newborn piglets, however, no effects on neurologic cell death at $24 \mathrm{~h}$ after the insult became apparent. Future studies are necessary to assess the long-term histologic outcome as well as the potential of these drugs in combination with other neuroprotective strategies.

Acknowledgments. The authors thank Evelyn van den Tweel, Tomoaki Ioroi, and Nicole Hamers for their help with the experiments and the histology. We also thank the biotechnicians of the Central Laboratory Animal Institute of the Utrecht University for their enthusiastic help during the experiments; Robin de Graaf for designing the MR sequences; Changlian Zhu, from the Perinatal Center in Göteborg, Sweden, for assisting in the caspase-3 measurements; Tessa Ververs, of the pharmacological department of the University Medical Center, Utrecht, the Netherlands, for the determination of the allopurinol and oxypurinol concentrations; Cheraar Leusink for technical support during the animal experiments; and Gerard van Vliet for constructing the MR head coils. The MRVI software package was kindly provided by the participants of the EU Network programmes: Human Capital and Mobility, CHRX-CT94-0432 and Training and Mobility of Researchers, ERB-FMRX-CT970160.

\section{REFERENCES}

1. Ferriero DM 2001 Oxidant mechanisms in neonatal hypoxia-ischemia. Dev Neurosc 23:198-202

2. Delivoria-Papadopoulos M, Mishra OP 1998 Mechanisms of cerebral injury in perinatal asphyxia and strategies for prevention. J Pediatr 132:S30-S34

3. Fellman V, Raivio KO 1997 Reperfusion injury as the mechanism of brain damage after perinatal asphyxia. Pediatr Res 41:599-606

4. Halliwell B 1989 Protection against tissue damage in vivo by desferrioxamine: what is its mechanism of action? Free Radic Biol Med 7:645-651

5. Gluckman PD, Williams CE 1992 When and why do brain cells die? Dev Med Child Neurol 34:1010-1014

6. Lorek A, Takei Y, Cady EB, Wyatt JS, Penrice J, Edwards AD, Peebles D, Wylezinska M, Owen Reece H, Kirkbride V, et al 1994 Delayed ("secondary") cerebral energy failure after acute hypoxia-ischemia in the newborn piglet: continuous 48-hour studies by phosphorus magnetic resonance spectroscopy. Pediatr Res 36:699-706
7. Shadid M, Moison R, Steendijk P, Hiltermann L, Berger HM, Van Bel F 1998 The effect of antioxidative combination therapy on post hypoxic-ischemic perfusion, metabolism, and electrical activity of the newborn brain. Pediatr Res 44:119-124

8. Van Bel F, Shadid M, Moison RMW, Dorrepaal CA, Fontijn J, Monteiro L, Van de Bor M, Berger HM 1998 Effect of allopurinol on postasphyxial free radical formation, cerebral hemodynamics, and electrical brain activity. Pediatrics 101:185-193

9. Marro PJ, McGowan JE, Razdan B, Mishra OP, Delivoria-Papadopoulos M 1994 Effect of allopurinol on uric acid levels and brain cell membrane $\mathrm{Na}+, \mathrm{K}(+)$-ATPase activity during hypoxia in newborn piglets. Brain Res 650:9-15

10. Palmer C, Towfighi J, Roberts RL, Heitjan DF 1993 Allopurinol administered after inducing hypoxia-ischemia reduces brain injury in 7-day-old rats. Pediatr Res 33:405-411

11. Hurn PD, Koehler RC, Blizzard KK, Traystman RJ 1995 Deferoxamine reduces early metabolic failure associated with severe cerebral ischemic acidosis in dogs. Stroke 26:688-694

12. Peeters-Scholte C, Koster JG, Veldhuis W, van den Tweel E, Zhu C, Kops N, Blomgren K, Bär D, van Buul-Offers SC, Hagberg H, Nicolay K, Van Bel F, Groenendaal F 2002 Neuroprotection by selective nitric oxide synthase inhibition at 24 hours after perinatal hypoxia-ischemia. Stroke 33:2304-2310

13. Naressi A, Couturier C, Devos JM, Janssen M, Mangeat C, de Beer R, GraveronDemilly D 2001 Java-based graphical user interface for the MRUI quantitation package. MAGMA 12:141-152

14. Wung WE, Howell SB 1980 Simultaneous liquid chromatography of 5-fluorouracil, uridine, hypoxanthine, xanthine, uric acid, allopurinol, and oxipurinol in plasma. Clin Chem 26:1704-1708

15. Whitaker JR, Granum PE 1980 An absolute method for protein determination based on difference in absorbance at 235 and $280 \mathrm{~nm}$. Anal Biochem 109:156-159

16. Kime R, Gibson A, Yong W, Hider R, Powers H 1996 Chromatographic method for the determination of non-transferrin-bound iron suitable for use on the plasma and bronchoalveolar lavage fluid of preterm babies. Clin Sci (Lond) 91:633-638

17. Felix B, Leger ME, Albe-Fessard D, Marcilloux JC, Rampin O, Laplace JP 1999 Stereotaxic atlas of the pig brain. Brain Res Bull 49:1-137

18. Peeters-Scholte C, van den Tweel E, Ioroi T, Post I, Braun K, Veldhuis W, Nicolay K, Groenendaal F, Van Bel F 2002 Pharmacological interventions in the newborn piglet in the first $24 \mathrm{~h}$ after hypoxia-ischaemia: a haemodynamic and electrophysiological perspective. Exp Brain Res 147:200-208

19. Williams GD, Palmer C, Heitjan DF, Smith MB 1992 Allopurinol preserves cerebral energy metabolism during perinatal hypoxia-ischemia: a 31P NMR study in unanesthetized immature rats. Neurosci Lett 144:103-106

20. Palmer C, Vannucci RC, Towfighi J 1990 Reduction of perinatal hypoxic-ischemic brain damage with allopurinol. Pediatr Res 27:332-336

21. Betz AL 1985 Identification of hypoxanthine transport and xanthine oxidase activity in brain capillaries. J Neurochem 44:574-579

22. Phillis JW, Sen S 1993 Oxypurinol attenuates hydroxyl radical production during ischemia/reperfusion injury of the rat cerebral cortex: an ESR study. Brain Res 628:309-312

23. Moorhouse PC, Grootveld M, Halliwell B, Quinlan JG, Gutteridge JM 1987 Allopurinol and oxypurinol are hydroxyl radical scavengers. FEBS Lett 213:23-28

24. Hudome S, Palmer C, Roberts RL, Mauger D, Housman C, Towfighi J 1997 The role of neutrophils in the production of hypoxic-ischemic brain injury in the neonatal rat. Pediatr Res 41:607-616

25. Ko KM, Godin DV 1990 Inhibition of transition metal ion-catalysed ascorbate oxidation and lipid peroxidation by allopurinol and oxypurinol. Biochem Pharmacol 40:803-809

26. Peterson DA, Kelly B, Gerrard JM 1986 Allopurinol can act as an electron transfer agent. Is this relevant during reperfusion injury? Biochem Biophys Res Commun 137:76-79

27. Lebon V, Petersen KF, Cline GW, Shen J, Mason GF, Dufour S, Behar KL, Shulman GI, Rothman DL 2002 Astroglial contribution to brain energy metabolism in humans revealed by $13 \mathrm{C}$ nuclear magnetic resonance spectroscopy: elucidation of the dominant pathway for neurotransmitter glutamate repletion and measurement of astrocytic oxidative metabolism. J Neurosci 22:1523-1531

28. Palmer C, Roberts RL, Bero C 1994 Deferoxamine posttreatment reduces ischemic brain injury in neonatal rats. Stroke 25:1039-1045

29. Feng Y, LeBlanc MH, LeBlanc EB, Parker CC, Fratkin JD, Qian XB, Patel DM, Huang M, Smith EE, Vig PJ 2000 Desmethyl tirilazad improves neurologic function after hypoxic ischemic brain injury in piglets. Crit Care Med 28:1431-1438

30. Cable H, Lloyd JB 1999 Cellular uptake and release of two contrasting iron chelators. J Pharm Pharmacol 51:131-134

31. Shadid M, Buonocore. G, Groenendaal F, Moison R, Ferrali M, Berger HM, Van Bel F 1998 Effect of deferoxamine and allopurinol on non-protein-bound iron concentrations in plasma and cortical brain tissue of newborn lambs following hypoxiaischemia. Neurosci Lett 248:5-8

32. deLemos RA, Roberts RJ, Coalson JJ, deLemos JA, Null Jr DM, Gerstmann DR 1990 Toxic effects associated with the administration of deferoxamine in the premature baboon with hyaline membrane disease. Am J Dis Child 144:915-919

33. Varani J, Dame MK, Diaz M, Stoolman L 1996 Deferoxamine interferes with adhesive functions of activated human neutrophils. Shock 5:395-401

34. Groenendaal F, Shadid M, McGowan JE, Mishra OP, Van Bel F 2000 Effects of deferoxamine, a chelator of free iron, on $\mathrm{Na}+, \mathrm{K}+$-ATPase activity of cortical brain cell membrane during early reperfusion after hypoxia-ischemia in newborn lambs. Pediatr Res 48:560-564

35. Dorrepaal CA, Berger HM, Benders MJ, Zoeren-Grobben D, Van deBor M, Van Bel F 1996 Nonprotein-bound iron in postasphyxial reperfusion injury of the newborn. Pediatrics 98:883-889

36. Weber E, Allegrini PR, Sauer D 1993 Assessment of infarct volume in the mouse brain: correlation of magnetic resonance imaging with morphometry. In Vivo 7:335338 